\title{
Pilot tones in WDM networks with wavelength converters
}

\author{
Kloch, Allan; Mikkelsen, Benny; Stubkjær, Kristian
}

Published in:

Optical Fiber Communication. OFC 97., Conference on

Link to article, DOI:

10.1109/OFC.1997.719654

Publication date:

1997

Document Version

Publisher's PDF, also known as Version of record

Link back to DTU Orbit

Citation (APA):

Kloch, A., Mikkelsen, B., \& Stubkjær, K. (1997). Pilot tones in WDM networks with wavelength converters. In Optical Fiber Communication. OFC 97., Conference on (pp. 24-25). IEEE.

https://doi.org/10.1109/OFC.1997.719654

\section{General rights}

Copyright and moral rights for the publications made accessible in the public portal are retained by the authors and/or other copyright owners and it is a condition of accessing publications that users recognise and abide by the legal requirements associated with these rights.

- Users may download and print one copy of any publication from the public portal for the purpose of private study or research.

- You may not further distribute the material or use it for any profit-making activity or commercial gain

- You may freely distribute the URL identifying the publication in the public portal

If you believe that this document breaches copyright please contact us providing details, and we will remove access to the work immediately and investigate your claim. 
internal noise figure due to additional gain compression by a feedback light is negligible. Therefore, one can improve the noise figure using, for example, fiber gratings, which will be implemented in our system in the near future.

1. A.K. Srivastava, Y. Sun, J.L. Zyskind, J.W. Sulhoff, C. Wolf, R.W. Tkach, in Optical Amplifiers and Their Applications, Vol. V, Trends in Optics and Photonics Series (Optical Society of America, Washington D.C., 1996), p. 24.

2. E. Desurvire, M. Zirngibl, H.M. Presby, D. Digiovanni, IEEE Photon. Technol. Lett. 3, 453-455 (1991).

3. M. Zirngibl, Electron. Lett. 27, 50-561 (1991).

4. J.F. Massicott, S.D. Willson, R. Wyatt, J.R. Armitage, R. Kashyap, D. Wiilliams, R.A. Lobbett, Electron. Lett. 30, 962-964 (1994).

5. H. Okamura, IEEE J. Lightwave Technol. 10, 1110-1116 (1992).

\section{Pilot tones in WDM networks with wavelength converters}

A. Kloch, B. Mikkelsen, K.E. Stubkjaer, Center for Broadband Telecommunications, Department of Electromagnetic Systems, Technical University of Denmark, Building 348 , DK-2800 Lyngby, Denmark; E-mail: ak@emi.dtu.dk

Supervision and management of future wavelength-division multiplexed (WDM) networks may be accomplished with pilot tones generated by amplitude modulation of the signal. ${ }^{1}$ This technique is attractive as no extra light source is needed to perform, e.g., signal power supervision throughout the network. However, because optical cross connects (OXCs) deploying wavelength converters are likely to be included in an optical network layer, ${ }^{2}$ and because wavelength converters generally have a nonlinear transfer function (in contrast to, e.g., couplers, filters, and erbium-doped fiber amplifiers), special attention must be given to how the conversion influences the pilot tones and vice versa.

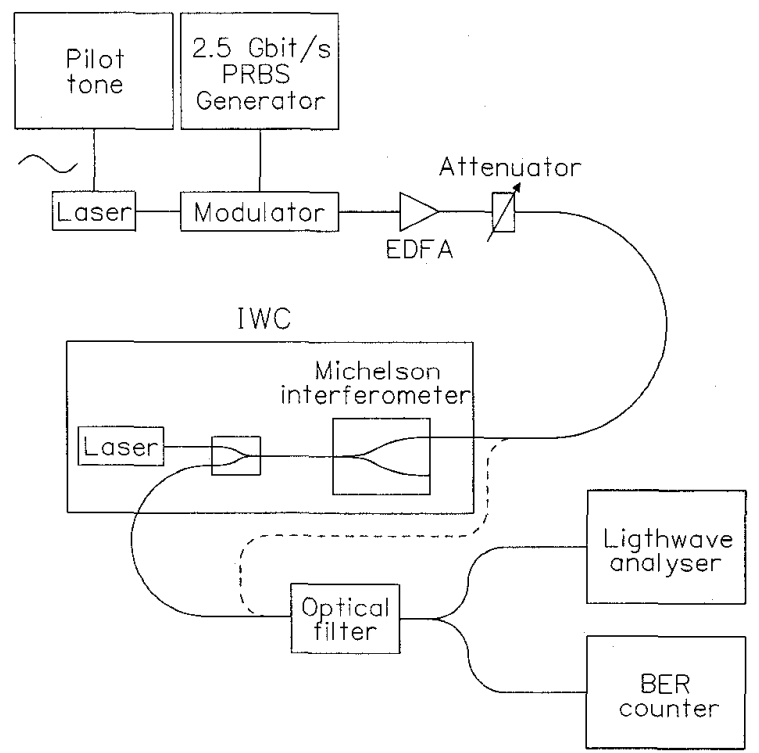

TuE6 Fig. 1. Experimental setup used for measurements on pilot tones transmitted through an IWC.
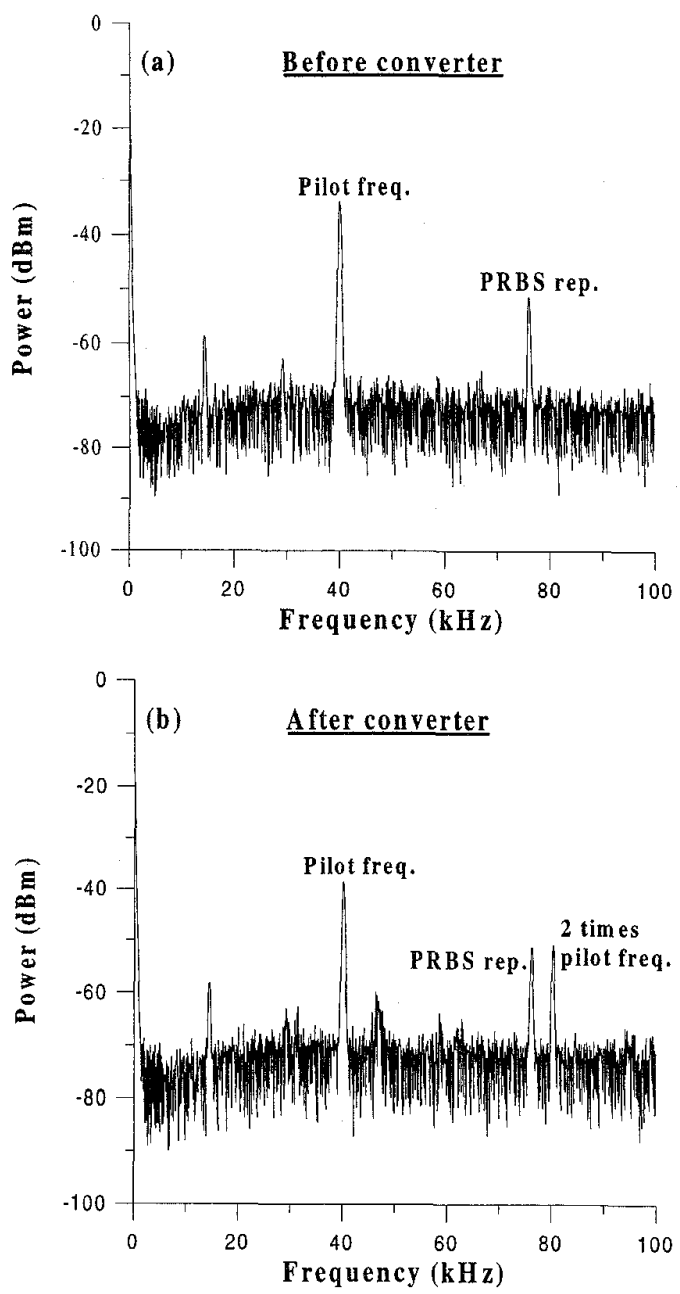

TuE6 Fig. 2. Low-frequency spectrum (a) before and (b) after the IWC. Pilot tone frequency: $40 \mathrm{kHz}$; electrical bandwidth: $300 \mathrm{kHz}$.

Here we investigate the transmission of a pilot tone through an interferometric wavelength converter (IWC) ${ }^{3}$ in conjunction with a 2.5 Gbit/s experiment as shown in Fig. 1. The pilot tone is added by sinusoi$\mathrm{dal}$ modulation of the bias current to the signal laser. After the IWC (Michelson interferometer) the converted signal is analysed using a bit-error-rate (BER) counter and a lightwave analyzer.

For a pilot tone frequency of $40 \mathrm{kHz}$ and a modulation index of 0.27 , the signal spectrum before and after the IWC are shown as Fig. 2(a) and Fig. 2(b), respectively. After the conversion a frequency component at $80 \mathrm{kHz}$ occurs while the pilot tone power-to-noise ratio is reduced by approximately $5 \mathrm{~dB}$. This behavior is explained by the sinusoidal transfer function of the converter. When an amplitude-modulated pilot tone is added to the bit sequence the nonlinear transfer function generates frequency components at multiples of the pilot frequency and the pilot tone power-to-noise ratio is reduced.

Figure 3 shows the power-to-noise ratio at the pilot frequency versus the modulation index before and after conversion. The reduction of the power-to-noise ratio due to conversion is nearly independent of the modulation index and varies from $3-5 \mathrm{~dB}$. The pilot tone power-tonoise ratio increases with the modulation index indicating that the best performance is obtained using a high modulation index. Further mea- 


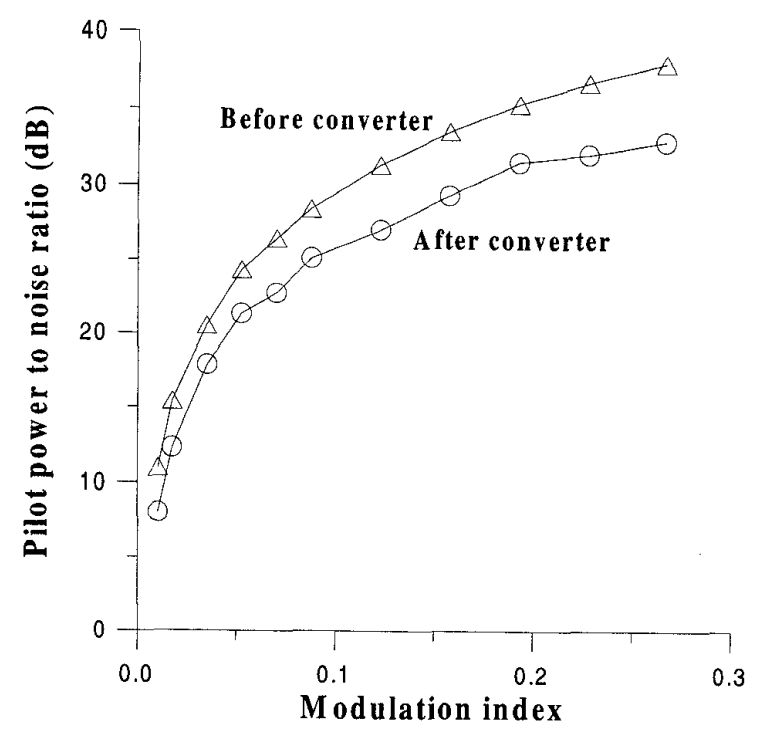

TuE6 Fig. 3. The power (at the pilot frequency) to noise ratio before and after the conversion as a function of the modulation index. Pilot tone frequency: 40 $\mathrm{kHz}$; electrical bandwidth: $300 \mathrm{kHz}$.

surements analyzing the BER performance of the converter have been carried out at $2.5 \mathrm{Gbit} / \mathrm{s}$ demonstrating that the power penalty (@BER = $10^{-9}$ ) remains below $1 \mathrm{~dB}$ for pilot tone frequencies from $10 \mathrm{kHz}$ to 10 $\mathrm{MHz}$ even for a high modulation index of 0.27 .

In conclusion, wavelength converters are found to be far from transparent to pilot tones. Although pilot tones can be added with a modulation index as high as 0.27 and still result in a conversion penalty below $1 \mathrm{~dB}$, the pilot tone power-to-noise ratio is reduced by $5 \mathrm{~dB}$ at each wavelength converter stage. Therefore, alternative schemes for the network supervision must be applied based on either (1) an extra wavelength channel dedicated to supervision or (2) blocking and retransmission of the pilot tone at each OXC. ${ }^{4}$ The latter approach, where the pilot tone is blocked and retransmitted when the signal wavelength is converted, possesses the additional advantage that the pilot tone can be used for wavelength identification.

1. G.R. Hill et al., IEEE J. Lightwave Technol. 11, 667-679 (1993).

2. Jourdan et al., IEEE J. Lightwave Technol. 14, 1198-1206 (1996).

3. F. Ratovelomanana et al, in Optical Fiber Communication Conference, Vol. 2, 1996 OSA Technical Digest Series (Optical Society of America, Washington, D.C., 1996), pp. 124-125.

4. Tada et al., IEEE Sel. Area Commun. 14, 914-922 (1996).
TuF

11:00am-12:30pm Room C241

The Global Drive for Fiber-In-The-Loop

Ed Harstead, Lucent Technologies, Inc., Presider

TuF1 (Invited)

11:00

Deutsche Telekom experiences with fiber-in-the-loop systems and future aspects

Manfred Rocks, Deutsche Telekom AG, Forschungszentrum, Ringbahnstraße 130, D-12103 Berlin, Germany; E-mail: rocks@fz.telekom.de

In 1992, Deutsche Telekom launched a large scale fiber-in-the-loop (FITL) three-year program, called OPAL. Later, another program with a slightly different aim, ISIS (Integrated System for optical network InfraStructure) was initiated and continues today. ${ }^{1-4}$ Both projects (Table 1) cover about 4 million lines, which will use optical fiber technology in the access network for communication. At the end-of-roll-out-phase, about $10 \%$ of all telephone customers will take advantage of this technique.

The OPAL and ISIS systems could only become reliable field-technology after intensive interaction by network operators and with strong industrial partners. The existing infrastructure limits the economic application of FITL systems in some cases. Therefore, decentral planning is advantageous. If a certain system manufacturer's systems have been installed in local regions, then this manufacturer has a good chance to also become the provider of subsequent orders for the area because the staff is acquainted with the existing technology.

ISIS technology has been developed by kabelmetal electric (ke). Meanwhile three other industrial manufacturers also deliver those systems. In contrast to OPAL technology, Telekom avoids a new plurality in different system types. In the future, FITL technology must have a broad, worldwide basis in order to further drop the prices for components and systems. This was one of the reasons for the launch of the international "Full Service Access Network" (FSAN) action. ${ }^{5}$ Because of the unexpected ISDN boom in Germany, in some cases, electronic hardware had to be replaced in the ONUs.

The system hardware and software is in permanent progress. Behavior observed on working OPAL 93 and 94 systems lead to the following innovations: new economic powering concepts of field equipment; new sizes of ONUs (for 200 subscribers); new housing type for curb-boxes; use of uniform optical equipment, e.g., connectors for all the different OPAL system types; transition from company specific interfaces to open interfaces like V5.x; and a trend towards uniform management systems.

TuF1 Table 1. Roll-out of Optical Access Network Technology (No. of 1000 lines)

\begin{tabular}{|c|l|r|r|r|r|c|}
\hline \multicolumn{2}{|c|}{ Year } & $' 93$ & '94 & '95 & '96 & TOTAL \\
\hline \multirow{2}{*}{ OPAL } & PON & 163 & 361 & 193 & 32 & 749 \\
\cline { 2 - 7 } & AON & 63 & 175 & 229 & 200 & 667 \\
\hline ISIS & indoor & & & 575 & 1.800 & 2.275 \\
\hline & outdoor & & & & 300 & 300 \\
\hline
\end{tabular}

